\section{RELACIO $\wedge$ ES}

Relaciones. Estudios de historia y sociedad ISSN: 0185-3929

relacion@colmich.edu.mx

El Colegio de Michoacán, A.C

México

Martínez Aguilar, José Manuel

El aserradero de Zatzio, un caso de la explotación de los bosques en Michoacán

Relaciones. Estudios de historia y sociedad, vol. XXXII, núm. 127, 2011, pp. 195-221

El Colegio de Michoacán, A.C

Zamora, México

Disponible en: http://www.redalyc.org/articulo.oa?id=13719806007

- Cómo citar el artículo

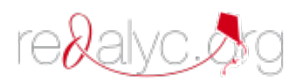

- Número completo

- Más información del artículo

Página de la revista en redalyc.org

Sistema de Información Científica

Red de Revistas Científicas de América Latina, el Caribe, España y Portugal

Proyecto académico sin fines de lucro, desarrollado bajo la iniciativa de acceso abierto 


\title{
El aserradero de Zatzio, un caso de la explotación de los bosques en Michoacán
}

\author{
José Manuel Martínez Aguilar* \\ UNIVERSIDAD MICHOACANA DE SAN NICOLÁS DE HIDALGO
}

El trabajo hace referencia a la explotación de los bosques en el distrito de Ario de Rosales, Michoacán, durante las primeras cuatro décadas del siglo xx, por parte de los empresarios norteamericanos Santiago Slade y James J. Slade Jr. Se hace énfasis en un caso de estudio: el aserradero de Zatzio, el pueblo que se construyó para sus trabajadores y la forma de vida de los mismos empleados y sus familias.

(Deforestación, Zatzio, Santiago Slade, Michoacán)

\section{INTRODUCCIÓN}

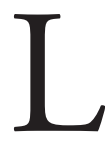

a consolidación y el desarrollo del modelo económico capitalista de fines del siglo XIX en Michoacán significaron la apertura comercial hacia mercados nacionales e internacionales, durante la administración de Aristeo Mercado, cuyo gobierno (1891-1911) representó precisamente el periodo de activación económica. A la puesta en marcha de este programa económico, contribuyó la llegada de empresarios y capitales franceses, norteamericanos, ingleses, alemanes y españoles que, junto a un reducido grupo de capitalistas y grandes propietarios mexicanos, conformaron una elite social que promovió para su beneficio el desarrollo material del estado, acaparando las riquezas de los montes, del campo y del subsuelo michoacanos. Muchas de estas manifestaciones de poder se presentaron más allá del inicio y fin de la Revolución mexicana, como el

\footnotetext{
*majmanuel999@hotmail.com
} 
caso de las empresas forestales que eran propiedad de Santiago Slade y su hijo James J. Slade, que referiremos aquí.

El presente trabajo pretende tener un acercamiento a la manera como se explotaron los recursos madereros de una parte de Michoacán durante las primeras décadas del siglo xx. Se aborda el caso específico del aserradero de Zatzio (Tzatzio), uno de los más importantes del país de 1928 a 1940, propiedad de Santiago J. Slade y su hijo James J. Slade. Ya que su funcionamiento dependía de la mano de obra de un buen número de trabajadores, Slade mandó construir un considerable número de casas para ellos y sus familias, en terrenos colindantes al antiguo Zatzio, entre Ario de Rosales y Tacámbaro. Con base en importantes trabajos publicados, documentos de archivo y testimonios de personas que habitaron el lugar se hizo una reconstrucción de la formación de la empresa Tzatzio y Anexas S.A. que dio vida al nuevo poblado, las características del sitio, incluyendo el aserradero, así como de la forma de vida de los trabajadores y sus familias. La investigación muestra dos perspectivas del mismo problema: una, donde se aprecia un excesivo aprovechamiento de los recursos forestales en detrimento de algunas comunidades que fueron poco remuneradas y, otra, donde predomina un sentimiento de prosperidad y satisfacción de los trabajadores del aserradero y sus familias por el modo de vida ofrecido por los empresarios norteamericanos.

\section{LAS EMPRESAS de SLADE}

En 1898, la Compañía de Maderas Read y Campell de propietarios ingleses, vendió el aserradero Las Palomas ${ }^{1}$ a la Michoacán Transportation Company, filial de la Compañía Nacional de Maderas, S. A., propiedad de Santiago Slade, George Kennedy y Santiago Snell. ${ }^{2}$ El

${ }^{1} \mathrm{El}$ aserradero, que se encontraba cerca de Tingambato fue vendido incluyendo maquinaria, útiles, instrumentos, mobiliario, bueyes, caballos, mulas, burros y cuanto allí existía. Además de derechos y acciones para cortar madera en los montes de Tingambato, Turicato, San Ángel y Comachuén., J. Napoleón Guzmán Ávila, Michoacán y la inversión extranjera 1880-1911, Morelia, UMSNH, Departamento de Investigaciones históricas, 1982, 111.

${ }^{2}$ Álvaro Ochoa Serrano, Repertorio Michoacano 1889-1926, Zamora, El Colegio de Michoacán, 1995, 378. 
aserradero con nuevo nombre y dueños reinició sus operaciones en 1901, después de cerrar varios contratos de arrendamiento del bosque, ante el enorme potencial de madera aprovechable de la región de Uruapan. ${ }^{3}$ Con la introducción del ferrocarril a Uruapan a fines del siglo XIX, la región boscosa de Pátzcuaro-Uruapan fue más expuesta a la extracción de madera, por lo que para 1910 esta zona era la más devastada del estado. ${ }^{4}$ En las cercanías de Tingambato y Turicato la Read y Campell había explotado los cerros de Cumburinda, Triquio, Piedras Cuatas, Cerro de la Virgen y Cerro Cuate, así como otra área boscosa en las cercanías de Erongarícuaro. ${ }^{5}$ La Compañía Nacional de Maderas de Slade había comprado el aserradero de las Palomas, en las cercanías de Tingambato, a Gabriel Vargas, ${ }^{6}$ Valentin Montaño, Domingo Narvarte y Francisco Vallejo, y tenía derechos de monte en Parangaricutiro, Paricutín, Pichátaro, Cherán, Paracho, Urapicho, Aranza, Angahuan, tenían una vigencia de explotación maderera de 30 años y prohibían a los comuneros cultivar los terrenos silvícolas, en cambio éstos recibían una renta anual, pero era pagada por Slade al gobierno del estado. ${ }^{7}$ Los pagos se hacían a través del Monte de Piedad del Estado, creado en 1880, el cual a su vez repartía los depósitos entre los comuneros indígenas en partes iguales, pero el dinero a menudo no llegaba a la comunidad correspondiente, por lo que las quejas de los comuneros en voz de sus apoderados legales eran frecuentes. ${ }^{8}$

Para 1903, el mismo Santiago Slade había formado la Mexican Finance Company. En 1907, la compañía Bosques Mexicanos y, un

${ }^{3}$ La compañía también hizo un convenio entre el señor Santiago J. Slade Jr. y Anastacio Vargas representante de la comunidad de Comachuen para la venta de sus montes; el precio pactado fue de $\$ 10,000$ con una duración de diez años.

${ }^{4}$ Esperanza Fujigaky Cruz, Historia de la cuestión agraria mexicana (1890-1910), México, Siglo XXI - Cенам, 1998, 37.

${ }^{5}$ J. Napoleón Guzmán, op. cit., 1982, 109-110.

${ }^{6}$ Gabriel Vargas había explotado los bosques de Tingambato sin medida. Como los comuneros que intentaron impedirlo fueron arrestados un mes. Esto sucedió un año antes de ser presidente de Tingambato.

AHPM, Ramo: hijuelas, distrito de Uruapan, libro 17, 1901, fojas 96-97.

${ }^{7}$ Dietz Gunther, La comunidad P'urhépecha es nuestra fuerza: etnicidad, cultura y región en un movimiento indígena en Michoacán, México, Abya-Yala, Quito, 1999, 150.

${ }^{8}$ AHPEM, Ramo: Hijuelas, distrito de Uruapan, libro 18, 1906, Foja 93. Véase también AHPEM, Ramo: Hijuelas, distrito de Uruapan, libro 18, 1904, Foja 260. 
año después la Compañía Industrial de Michoacán, y deja como gerente a su hijo James J. Slade Jr., también conocido como J. J. Slade o como Santiago J. Slade Jr. ${ }^{9}$ A partir de este mismo año, Parangaricutiro, como tantas comunidades, se vio inmersa en la explotación del recurso silvícola al arrendar los montes a la Compañía Bosques Mexicanos. El contrato se hizo por 30 ańos a un costo total de $\$ 215,000.00 .^{10}$

El trazado de la red ferroviaria a Uruapan y los Reyes modificó el panorama económico y social de la sierra purépecha en forma radical. Los trenes permitían explotar comercialmente los copiosos bosques y por ello se despertó gran interés en compañías que deseaban arrendar. Para 1907 la Compañía industrial de Michoacán de Santiago Slade había realizado un contrato de explotación de bosques con la Sociedad Fernández y compañía de Homobono y Rafael Portugal. El acuerdo se realizó como contrato de sociedad mercantil en nombre colectivo, para explotar los montes que habían sido de la Compañía Industrial de Michoacán S. A., los bosques de la Compañía de Bosques Mexicanos S. A. y de la Sociedad Fernández y Compañía. ${ }^{11}$ En 1912, la Compañía Industrial de Michoacán S. A. adquirió todas las acciones y derechos sobre un terreno situado en las comprensiones del pueblo de Capácuaro a un precio de $\$ 1,700.00$. El mismo año la compañía compró cuatro terrenos al poniente de Tingambato, llamado "La Virgen”, a \$2,671.00; además logró un contrato de arrendamiento en Quinceo del distrito de Uruapan por $\$ 20,000.00$ y otro con la comunidad de Aranza por \$30,000.00. Para 1913, la compañía tenía en su poder contratos de arrendamiento que habían sido adquiridos a través de traspasos de compañías como Bosques Mexicanos y la Sociedad Fernández y Compañía. ${ }^{12}$ En resumen, des-

${ }^{9}$ Para esos años otras compañías habían iniciado operaciones en Michoacán: En 1901, la inglesa Michoacan Lumber, en 1908 y 1911 las norteamericanas The Pacific Timber Company y The Balsas Hardwood company, respectivamente. J. Napoleón Guzmán, op. cit., pp. 103-134.

${ }^{10}$ Carlos Paredes Martínez y Martha Terán, coord., Autoridad y gobierno indígena en Michoacán, El Colegio de Michoacán, INAH, UMSNH, 2003, 541.

${ }^{11}$ María Leticia Galván Silva, Inversiones extranjeras en Michoacán 1911-1940, Tesis de licenciatura en Historia, Morelia, Escuela de Historia, 2002, 66.

${ }^{12}$ Idem. 
de noviembre de 1907, hasta marzo de 1913 en la sierra purépecha se entregaron, en régimen de renta por treinta años, superficies forestales con una extensión de 220,000 hectáreas. El precio de las transacciones fue de $\$ 972,000$, que debían entregarse anualmente, a lo largo del periodo, en concepto de alquiler a las 20 comunidades tarascas involucradas. ${ }^{13}$ Para poder extraer la madera de los bosques se construyó una vía de ferrocarril que pasaría al pie de los cerros donde se iba a cortar la madera. La línea ferroviaria atravesaba las faldas de los montes pertenecientes a Nahuatzen, Cherán, Arantepacua, Capácuaro, Quinceo y otros; de este modo, resultaba relativamente fácil acarrear la madera de lo alto de los montes a la vía del tren. ${ }^{14}$

Jesús Castillo, originario de Paracho, narra como un grupo de hombres extraños en su aspecto y en su quehacer hicieron su aparición en la sierra purépecha:

Unos con botas y polainas manejaban las Autoridades civiles y otras manejaban instrumentos y aparatos, como "anteojos de larga vista", señalando sitios y puntos en donde dejaban mojoneras, cuyo significado la gente no entendía. Poco a poco se fue sabiendo que eran brigadas de una compañía de deslindes de los montes [...] Que tenia derecho a cortar los pinos y para ello estaban instalando "campamentos" en donde concentrar personal, aparatos y maquinaria [...] Y con una celeridad de "evidente progreso" la Compañía de Santiago Slade abrió brechas entre los cerros, contratando gente para construir en tajos y terraplenes, las vías del tren [...] Los Representantes de las Comunidades indígenas tuvieron la noticia de que tal compañía había recibido del Gobierno la autorización para explotar los montes, y que derivado de ello, los pueblos recibirían notorios beneficios: la comunicación ferroviaria, trabajo para la gente y un pago que se abonaría a favor de la comunidad. Luego se supo que tal pago era de tres centavos por cada pino que se derribara para aserrar su madera. ${ }^{15}$

${ }^{13}$ J. Napoleón Guzmán, op. cit., 1982, 123-125. Algunas de las comunidades afectadas fueron Capacuaro, Parangaricutiro, Arantepacua, Quinceo, San Lorenzo, Zirosto, Pamatácuaro, Urapicho, Cocucho, Sicucho, Paricutín, Tanaco, San Felipe, Pomacuarán, Angahuan, Cherán, Pichátaro y Aranza.

${ }^{14}$ Lucía García López, Nahuatzen, agricultura y comercio en una comunidad serrana, Zamora, El Colegio de Michoacán, Conacyt, 1984, 39.

${ }^{15}$ Idem. 
Figura 1. Ferrocarril que pasaba por Ario de Rosales, 1935 (Hurtado 2009, 69).

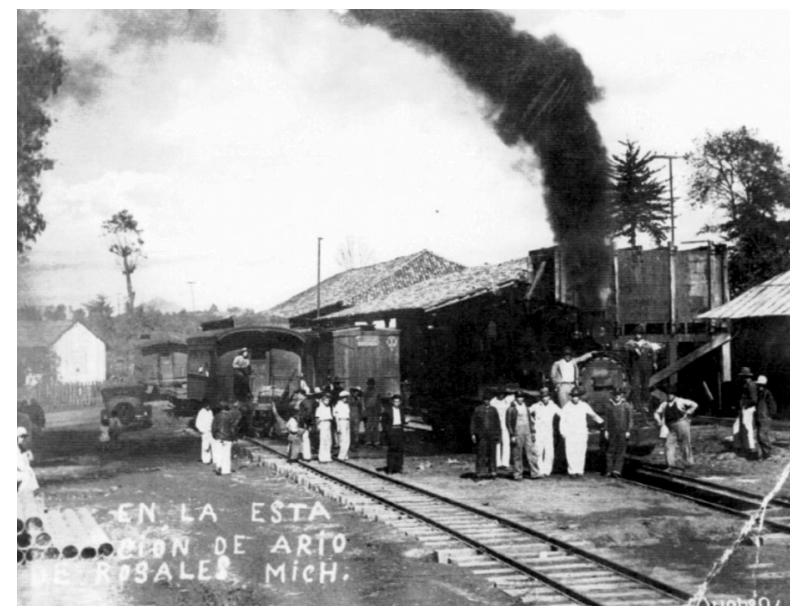

Estos contratos, lesivos a los intereses de la comunidad, generaron serios conflictos. Algunos inconformes, como Casimiro Leco, de Cherán, dirigió a un grupo de comuneros para recuperar tierras que habían sido arrendadas para la extracción de madera, lo cual puso en conflicto seriamente a las compañías de los Slade, al impedir temporalmente que el bosque fuera saqueado. Otros comuneros de Nurio, Cheranhátzicurin y Paracho que se manifestaron contra el corte de árboles fueron encarcelados; incluso un vecino de Cherán de nombre Federico Tapia fue asesinado al querer impedir un contrato de arrendamiento con la Compañía Industrial de Michoacán. Otro más de nombre Miguel Díaz fue ultimado por defender indígenas de Nurio. ${ }^{16}$ Debido a las manifestaciones en aumento, Santiago Slade formó un grupo de hombres armados para defender sus intereses entregándoles él mismo armas. Al mando de Praxedis Martínez y Gabriel Vargas, los hombres de Slade ultimaron a indígenas en diferentes pueblos, con el pretexto de ser enemigos de su compañía. ${ }^{17}$

${ }^{16}$ En 1913, Casimiro Leco de Cherán había armado a 150 hombres para desalojar la compañía de los bosques de la meseta. J. Napoleón Guzmán, op. cit. pp. 133-134.

${ }^{17}$ Ibid., p. 134. 
Figura 2. Estación de ferrocarril de Ario de Rosales (Boehm de Lameiras 1995, 114).

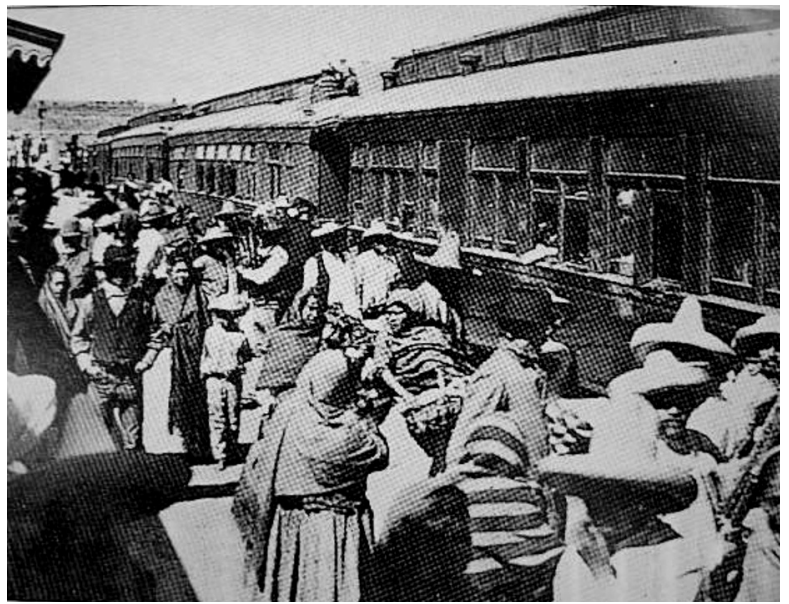

Tales conflictos y los originados por el movimiento de la Revolución en la entidad, incluyendo los que ocasionó el famoso bandolero Inés Chávez, quien en varias ocasiones asaltó e incendió trenes y otras pertenencias de la compañía de los Slade, mostraron los primeros indicios de pérdidas en la Compañía Industrial de Michoacán S. A. Sin embargo, unos años más tarde, en 1921, la misma compañía recobraría impulso al fusionarse con la Compañía del Ferrocarril Central de Michoacán S. A. para trabajar en la construcción de ferrocarriles, la explotación de terrenos petrolíferos, la explotación de bosques y el trabajo de la madera. Un año más tarde, no conforme con los predios adquiridos o arrendados hasta estas fechas, el mismo Slade compró tres predios en Zirahuén, por un costo de $\$ 1,500.00 .^{18}$

Aunque una ley agraria de 1915, determinaba que todos los acuerdos posteriores a 1856, en donde las tierras, bosques y recurso hídricos que hubieran sido expropiados a las comunidades quedaban anulados, sin embargo, dicha legislación tuvo poco efecto y

${ }^{18}$ Ibid., p. 68. 
para 1928 se prorrogó el contrato de la Michoacán Transportation Company, por diez años adicionales. En 1931, Lázaro Cárdenas, gobernador de Michoacán, envió al congreso una Ley, para restituir definitivamente los bosques de las comunidades indígenas que estaban siendo explotados, ${ }^{19}$ aún así, la compañía de Slade trabajaría sin impedimento por diez años más. Una vez que se terminó su contrato (o que terminaron con la madera accesible), la compañía industrial se llevó sus máquinas, levantó sus vías incluyendo todo el material utilizado en la construcción de pequeños puentes, y desapareció para siempre, dejando estas comunidades no sólo sin bosque, sino también sin trabajo. ${ }^{20}$

\section{Los Slade en Zatzio}

El problema de la deforestación en la zona de Ario de Rosales tuvo su origen a inicios del siglo xx, pero fue hasta 1925, bajo el régimen presidencial del general Calles, cuando el gobernador interino Sidronio Sánchez Pineda le otorgó una concesión al señor Santiago Slade, quien para entonces era gerente de la Compañía Michoacana Transportation Company S. A., para que construyera una línea de ferrocarril entre la estación de Ajuno y la población de Huetamo. ${ }^{21}$

En 1928, Slade realizó un contrato de compra-venta que correspondía a toda la madera de la hacienda de Chuén, donde el señor Valencia, dueño de la hacienda, recibiría un mínimo de \$36,000.00 por concepto de madera y carbón. La compañía Tzatzio y Anexas $S$. A. obtuvo permiso para construir dentro de la misma hacienda una vía férrea, con la condición de que fuera permanente y de utilidad pública. ${ }^{22}$ De esta forma, la empresa pudo explotar los montes madereros de los ricos bosques de Zatzio, Chuén y otros pueblos. El

${ }^{19}$ Eitan Gitzberg, Lázaro Cárdenas Gobernador de Michoacán 1928-1932, Morelia, El Colegio de Michoacán, umsnH, 1990, 208-209.

${ }^{20}$ Lucía García López, Nahuatzen, op. cit., p. 39.

${ }^{21}$ En los primeros años se habían cortado unos 800 mil árboles. Jesús Romero Flores, Diccionario michoacano, historia y geografia, Morelia, Gobierno del Estado de Michoacán, 1960, 331-332.

${ }^{22}$ J. Napoleón Guzmán, op. cit. pp. 133-134. 
Figura 3. Locomotora en la hacienda La Palma, Zatzio, Mich., 1940 (Hurtado 2010, 68).

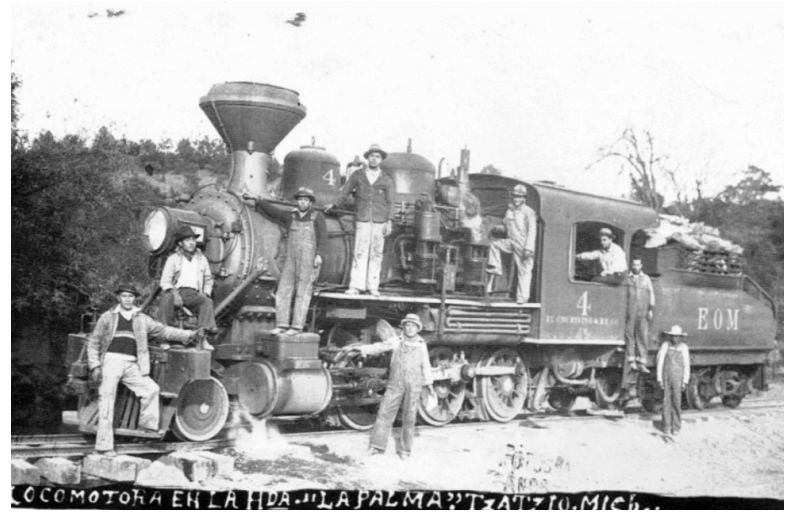

trabajo consistía en el corte de árboles para producir madera en diferentes medidas para su comercialización, como el pino rizado y pinoteca, en condiciones de trozas o tablas. La venta de esta madera le permitió a la compañía adquirir un prestigio importante como comercializadora de una de las maderas más limpias de nudos en todo el estado. ${ }^{23}$

Para 1933, la Compañía Michoacana Transportation Company S. A. era dueńa del ramal Ajuno a Ario, Tacámbaro, Sorucio y El Jabalí, así como 10 locomotoras de vapor (plataforma, locomotoras, carros caja, 2 coches de pasajeros, divididos en primera y segunda clase y tres carros express) y 14 carrozas para trozos, que incluían talleres para refacciones (maquinaria, herramienta y refacciones) también herramientas de vías, casas de empleados, derechos de vía y algunos enseres mas. ${ }^{24}$ Por estas fechas, la Compañía Industrial de Michoacán, de Salde, había arrasado con los bosques del distrito de Ario, talando unos 800 mil árboles. Casi toda la región por donde pasaba el ferrocarril, que iba de Ajuno a Ario estaba sobreexplotada. ${ }^{25}$

${ }^{23}$ María Leticia Galván Silva, op. cit. p. 73.

${ }^{24}$ María Leticia, op. cit., p. 71.

${ }^{25}$ Enrique Florescano, coord., Historia general de Michoacán, Gobierno del Estado de Michoacán, Instituto Michoacano de Cultura, 1989, 61-62. 
Figura 4. Personal de los talleres mecánicos de Zatzio (Hurtado 2010, 73).

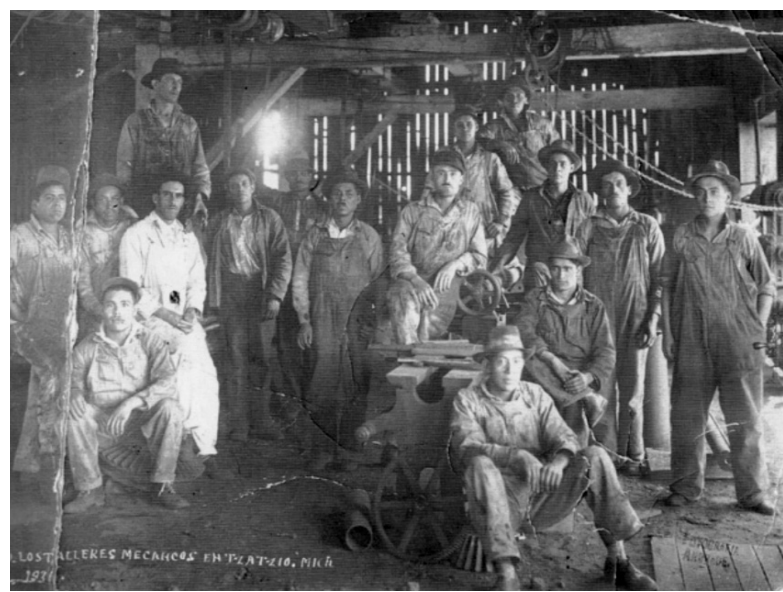

Figura 5. Locomotora de Ajuno a Ario de Rosales 1937 (Hurtado 2010, 71).

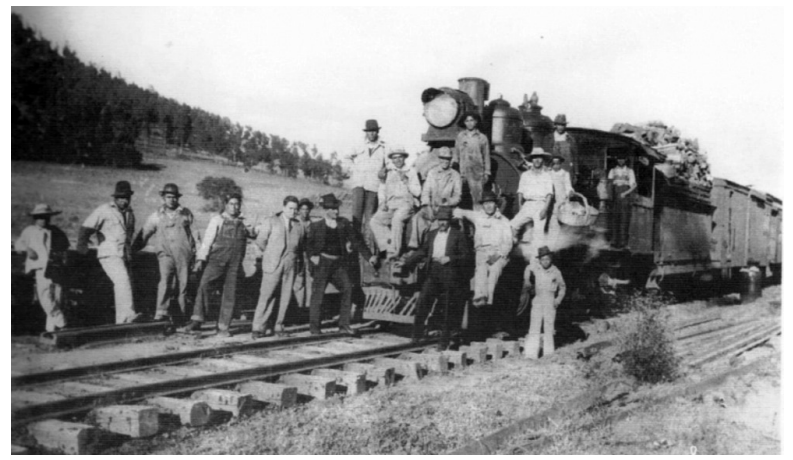

El ferrocarril partía del aserradero de Zatzio rumbo al Tepamal, para trasladar la madera a la estación de Ajuno, donde se entroncaba con la línea a Pátzcuaro-Morelia-México, hacia sus diferentes destinos. Entre los clientes que tenía la compañía de Slade se encontraba una empresa de Celaya, de nombre La Favorita, a quien se le surtió de duela y vigueta tras un contrato por $\$ 54,700$. También se sabe 
Figura 6. Personal de la locomotora de Zatzio, 1935-1937 (Hurtado 2010, 71).

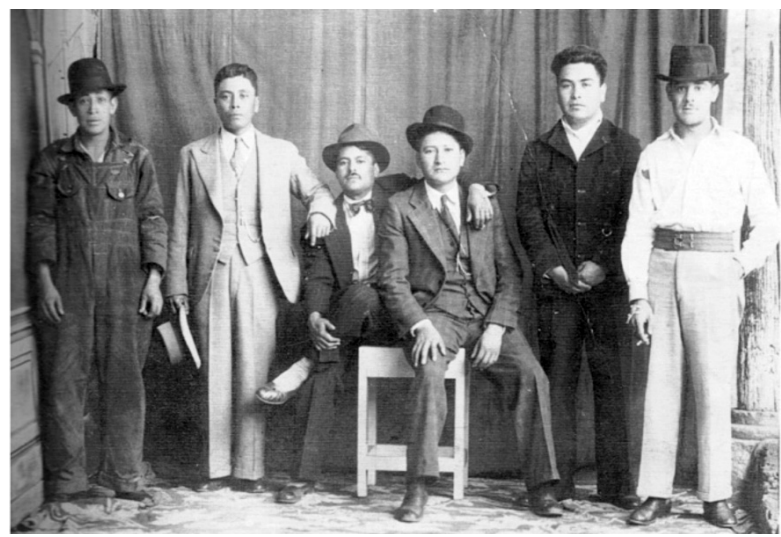

que vendió 40 millones de pies de madera a la compañía minera Rudston Read. Incluso, la importante compañía Dos estrellas de Tlalpujahua hizo un contrato por cuatro o cinco millones de pies cuadrados de ocote de oyamel, que se entregarían durante cinco ańos, y otro por tres a cinco millones de pies cuadrados anuales. ${ }^{26}$ Otro de sus principales compradores era Ferrocarriles Nacionales, cuyos dirigentes solicitaban a la compañía de Slade enormes cantidades de madera de encino para durmientes, con los que estaban construyendo líneas férreas en varias partes del país, ${ }^{27}$ las cuales eran entregados con acabado de hacha y perforadas, listas para su colocación, a 65 centavos por pieza. ${ }^{28}$

Para 1941, el ferrocarril de Ario realizaba sus últimas corridas, ya que la empresa se retiraba, pues los contratos de arrendamiento se habían vencido y las vedas impuestas por Lázaro Cárdenas no permitían renovarlos. Se sabe que en varias ocasiones las compañías de Slade se declaraban en quiebra, posiblemente como estrategia para evadir impuestos fiscales, como sucedió en 1905 con la Compañía

${ }^{26}$ J. Napoleón Guzmán, op. cit. p. 132-133.

${ }^{27}$ Ibid. p. 80.

${ }^{28}$ Miguel Guerrero de 89 años, quien trabajó en el aserradero Zatzio de 1928 a 1938. Entrevista hecha por J. Manuel Martínez agosto de 2009. 
Nacional de Maderas que se declaró en bancarrota y ofreció bienes a la empresa Mexican Finance Lumber Company. ${ }^{29}$ En esta ocasión, unos ańos antes, la Michoacán Transportation Company y la Compañía Tzatzio y Anexas, S. A. representadas por Santiago J. Slade, habían traspasado a la Compañía Ferrocarrilera y Maderas de Michoacán S.A. la concesión para la construcción del ferrocarril y la explotación de los bosques de Zatzio; vendiendo parte del aserradero, incluyendo maquinaria. Después de 1941 al haber desaparecido la compañía de Zatzio, el pueblo nuevo también se desintegró, quedando decenas de familias sin trabajo.

\section{DESCRIPCIÓN DEL PUEBLO Y ASERRADERO}

Cuando se construyó el aserradero, decenas de familias de Ario de Rosales, Pátzcuaro, Puruándiro, Tiripetío, Zacapu, y otros lugares cercanos llegaron a Zatzio, al tener noticias de que habría trabajo en ese lugar. La empresa, Compañía Tzatzio y Anexas, S. A., construyó al menos cuatrocientas casas de madera, que estaban agrupadas de cuatro en cuatro, formando manzanas cuadradas y calles rectas de terracería. ${ }^{30} \mathrm{El}$ pueblo, pues, tenía una traza reticular, de unas diez o doce calles en cada sentido, con su placita al centro, que abarcaba cuatro manzanas. En su auge, el pueblo nuevo debió tener alrededor de dos mil personas, el triple de habitantes que la población que ya existía en el lugar antes de que llegara la empresa.

Zatzio (Tzatzio) era un pequeño asentamiento cercano a la ciudad de Ario de Rosales, donde se estableció un aserradero de grandes dimensiones en 1928, a decir de algunos que estuvieron ahí, uno de los más grandes de México, que dio trabajo a numerosas familias de la región. Durante unos años, todo parecía funcionar adecuadamente, tanto para los empresarios, como para los trabajadores que tenían una casa donde vivir y un trabajo que parecía seguro, pero no así para los intereses del pueblo michoacano, pues el bosque estaba siendo destruido rápidamente y no se reforestaba al mismo ritmo.

${ }^{29}$ Ibid., p. 170.

${ }^{30}$ Hechas con madera de segunda o con madera sobrante del mismo aserradero. 
Las casas donde vivían los trabajadores median 10 x 10 metros, y se encontraban al centro de predios de unos $15 \times 25$ metros, delimitadas por cercas de fajillas. En medio de los lotes se concentraban las construcciones, que estaban levantadas unos ochenta centímetros del suelo, fabricadas por el exterior con tablas colocadas verticalmente, y al interior con duela; con techos a dos aguas, formados con morillos y cubiertos con tejamanil. Se accedía a las casas por medio de un portal, de unos tres metros de ancho por todo el largo de la casa. Los interiores estaban compuestos por dos cuartos de unos 24 metros cuadrados cada uno, separados por un pasillo que llegaba hasta la cocina, la cual debió tener unos dieciséis metros cuadrados. Tanto las recámaras, como la cocina tenían una ventana cada una, que daba hacia el exterior. En cada una de las recámaras se podían colocar unas dos camas o catres, por lo que las casas tenían capacidad para albergar familias de cuatro a ocho integrantes. Las cocinas solían tener un trastero, una mesita y un fogón, donde las señoras cocinaban y hacían diariamente las tortillas. Cada predio contaba con su noria, que se localizaba en alguna parte dentro del solar; en el resto del predio se plantaban árboles de cerezos, higos, manzanos, duraznos y otras frutas, o se construían chiqueros y gallineros para la crianza de animales domésticos, aunque también era común ver gallinas, patos o guajolotes sueltos en el solar. Las casas de los dueños de la empresa, sus familiares y personas de confianza, como Fernando Guerrero, la de Rafael Villegas y la de Cipriano Cerda, estaban entre el aserradero y el pueblo de abajo. Eran casas grandes de madera, tipo "americano": con su portal y su techo inclinado, pero de hechura más elaborada que el resto de las viviendas.

En el pueblo también había un molino, donde todas las amas de casa llevaban a moler su maíz para las tortillas. La manera más común de pagar el servicio del molino era con unas fichas de plástico compradas previamente ( 1 centavo, 2 y 2.5). También estaban establecidos herrería, carnicería, frutería, verdulería, etcétera. ${ }^{31}$ Además los domingos vendían alrededor de la plaza otros productos como carnitas o chicharrón. Por las noches algunas personas sacaban pues-

${ }^{31}$ Idem. 
Figuras 7 y 8 . Reconstrucción de la casa de la familia Arias, según descripción de José Martínez (Elaboración del autor).
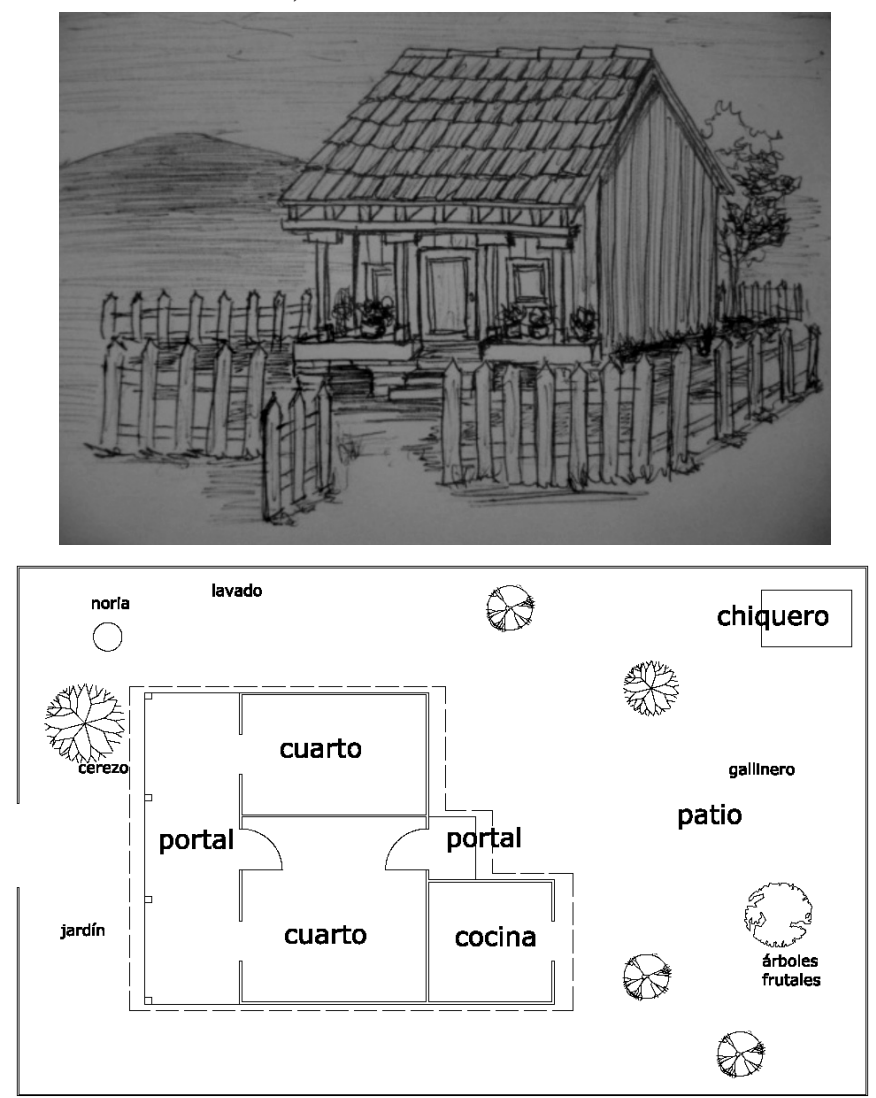

tos de comida, como pozole, tamales, atole, enchiladas, entre otras cosas. Además se contaba con un salón de baile y una escuela primaria, atendida por dos maestros. Para 1941, se encontraba en construcción una capilla de adobe y madera, pero nunca se concluyó totalmente por el cierre de la compañía. ${ }^{32}$

32 José Martínez Arias de 79 años (falleció en 2009), originario de Ario de Rosales. Entrevistas hecha por J. Manuel Martínez de enero a agosto de 2009. 
En el pueblo antiguo (de abajo), se encontraba una placita y otras tiendas, pero lo más importante del lugar era una hacienda, cuyo casco era de muros adobe y cubierta de viguería de madera y teja. La hacienda pertenecía a don Homobono Portugal y a su hermano Rafael, quien años atrás habían realizado varias transacciones con los Slade.

El aserradero de Zatzio se encontraba entre el pueblo de abajo, que era el pueblo viejo, localizado hacia el oriente, y el pueblo de arriba o nuevo, que estaba hacia el poniente. ${ }^{33}$ Se trataba de un gran aserradero compuesto por varias naves que fungían de talleres: taller de cepillos, taller de duela, taller de sierra, etcétera. Una de estas naves era de dos pisos, construidas con bases de concreto, estructura metálica y pisos de madera; las cuales funcionaban con la maquinaria más moderna que había en la época: máquinas hidroneumáticas, estufas de secado o calderas, desorilladora, cepilladora, péndulo, canteadoras, grandes sierras circulares, etcétera. Contaba con un patio de maniobras o almacenaje de considerables dimensiones cercado con capote, donde se apilaba la madera seca de diferentes clases y medidas. ${ }^{34}$ Los productos madereros que llegaban al aserradero eran grandes y gruesos trozos, de pino, oyamel, cedro y encino, que se bajaban de lo alto de los cerros con bueyes, hasta las faldas, por donde pasaban los trenes y eran cargadas a unas plataformas que llamaban "arańas". Los troncos de madera llegaban hasta el aserradero, donde los descargaban, desflemaban en una zanja con agua y procesaban, antes de convertirlas en vigas, vigueta, fajillas, morillos, polines, tablas, tablones y duela. Esta última se hacía en otro espacio dentro del mismo aserradero. ${ }^{35}$

Para sacar la madera procesada, el tren entraba a un lado del patio de almacenaje, quedando la parte más alta de los furgones al nivel de piso, para cargar los productos más fácilmente. ${ }^{36} \mathrm{~A}$ unos

${ }^{33}$ Los habitantes comentan que había dos aserraderos en el mismo lugar y de la misma empresa. Uno pequeño y otro de grandes dimensiones. Miguel Guerrero, op. cit.

${ }^{34}$ Había una máquina trituradora de desperdicio de madera que le llamaban "puerco". Miguel Guerrero, Idem.

${ }^{35}$ José Martínez Arias, op. cit.

${ }^{36}$ Jesús Martínez Velásquez, de 81 años, habitante de Zatzio señala con la mano ha- 
metros de ese lugar se encontraba un taller para servicio de los trenes, y cerca de ahí, hacia el sur del pueblo, se encontraban las casas de los ferrocarrileros, un poco separadas del resto del pueblo. El aserradero también contaba con baños rusos o vapor, que podían ser usados por los empleados al término de las actividades. La jornada de trabajo era de 8:00 a 1:00 pm y de 2:00 pm a 5:00 pm. De 1:00 a 2:00 los trabajadores salían a comer, a excepción de los encargados de la caldera, a quienes sus familiares les llevaban la comida. ${ }^{37}$ Ya que los baños y las calderas funcionaban con agua, existían en lo alto del pueblo tanques elevados que la suministraban, para que no faltara el líquido había una represa artificial que captaba el agua de lluvia. ${ }^{38}$

El administrador del aserradero, que se llamaba Fernando Guerrero, había dado facilidades a su hijo Jesús y a su sobrino Miguel, para tener un buen puesto en el aserradero. Miguel Guerrero, subió de "categoría" y sueldo, conociendo todo el proceso de producción. Desde los 8 o 9 años comenzó de virutero (recogiendo la viruta) y después fue realizando otras actividades: "Ganaba 5 centavos y en poco tiempo me subieron a 2.50". ${ }^{39}$ El encargado de pagar la "raya”, era un señor blanco y robusto, de nombre Rafael Villegas, quien entregaba a la mayoría de los trabajadores 2.00 o 2.50 pesos de monedas de plata; a otros 4 pesos y a otros 8 , dependiendo del puesto que tenían. Para ello, los trabajadores se formaban, y cuando tocaba su turno, se quitaban sus gorras para ahí recibir el dinero. ${ }^{40}$ Otra manera de pago era por medio de vales: eran tarjetas con diferentes cantidades impresas, que eran perforadas cuando se compraba algo, en una tienda grande (Cooperativa), donde se ofrecía todo tipo de productos, que surtían en Ario de Rosales y Pátzcuaro. ${ }^{41}$

cia el suroeste donde se encontraba un tanque de agua, Entrevista hecha por J. Manuel Martínez, julio de 2009.

${ }^{37}$ Para entrar en la mañana se hacían 3 llamadas, con el sonido de un tren. Las otras llamadas para entrar y salir era un solo pitido.

${ }^{38}$ Miguel Guerrero, op. cit.

${ }^{39}$ Idem.

${ }^{40}$ Ignacio Campos Campos, de 79 años de edad, habitante del lugar e hijo de un músico. Entrevista hecha por J. Manuel Martínez, 1 de febrero de 2009.

${ }^{41}$ José Martínez Arias, op. cit. 


\section{LA VIDA COTIDIANA EN ZatZio}

Si bien, la explotación desmedida de los bosques de algunas regiones de Michoacán había causado perjuicios, tanto a la propia naturale$\mathrm{za}$, como a muchos comuneros que eran poco beneficiados con el arrendamiento de sus tierras, y al no tener posibilidad de trabajarlas decidían unirse a los empleados de Slade. Algunas de las personas que habitaron Zatzio, ignorando quizá el manejo de las empresas y de los perjuicios que pudieran generar, veían de manera inmediata el beneficio que les dejaba trabajar en el aserradero y tener una casa donde vivir. Por ejemplo, José Martínez Arias, que para entonces tenía sólo diez años, narró los años de prosperidad y agrado que pasó ahí con su familia hasta que se acabó el trabajo. ${ }^{42}$ "Era un pueblo muy bonito; con calles anchas y casas de madera 'tipo americano' [...] El fin de semana nos pagaban y nos íbamos a Ario al cine [...] Vivíamos muy contentos [...] Fueron los años más bonitos de mi vida. Vivía ahí sólo seis años y siento que fueron muchos más”. ${ }^{43}$

La familia Arias llegó a Zatzio en 1935, proveniente de Ario de Rosales. Para ese entonces el grupo familiar estaba compuesto por la señora María de Jesús García, de 48 años; Fidel Arellano Cázarez de 25; Salud Arias García, de 26; Julia y José Martínez Arias, de 9 y 4 años, respectivamente; y Amelia Arellano, de un ańo de edad. En Zatzio nacieron Cecilia, Javier y Alicia Arellano Arias y con el segundo matrimonio tuvo siete hijos, de los cuales, tres murieron en la infancia. Casi al mismo tiempo una hermana de doña Salud Arias: Agustina y sus hijos Rosario, Gabriel y Natividad, también llegaron al lugar. Otro de los hermanos de dońa Salud, Jesús, había vivido ahí un tiempo, pero para esta fecha se había ido a trabajar a la ciudad de México.

José Martínez platica que su mamá vendía fruta en la plaza del pueblo. Él desde muy chico, ayudaba a su familia; al principio en

${ }^{42}$ Entrevista hecha a Salud Arias García (falleció en 2007), de 94 años, originaria de Ario de Rosales. Septiembre de 2004.

${ }^{43}$ José Martínez Arias, op. cit. Otro comenta: "Eran bonitos aquellos tiempos, era un pueblo tranquilo y seguro, a mi ya no me tocaron los bandidos como Inés Chávez ni nada de eso; lo peor que he visto de violencia e inseguridad ha sido hasta ahora”. Miguel Guerrero, op. cit. 
labores domésticas, como dar de comer a los animales, lavar los chiqueros, arrimar la leńa o sacar agua de la noria para llenar unos tambos. Otras veces salía a la calle a vender fruta, después de la escuela. "Cuando había higos, mi mamá me mandaba a venderlos al pueblo. Una vez unas 'gringas' que habitaban una casa grande en el pueblo de 'abajo', me los compraron todos; así que las próximas veces que mi madre me daba higos para venderlos me iba directamente a la casa de esas señoras, quienes los compraban con gusto".

Por aquel entonces, la familia Arias no tenía problemas económicos, ya que dońa Salud tenía algunos centavos gracias a su "puesto" de fruta y Fidel ganaba bien, incluso mucho más que los trabajadores comunes del aserradero.

Mi padrastro Fidel, que para mi era como un padre, era el encargado del orden del pueblo [guardia rural]. Para desempeñar su trabajo le habían dado pistola y escopeta [...] Cuando alguien cometía un delito, él era el responsable de llevarlo detenido a Ario [...] Mientras que los demás ganaban dos pesos o dos con cincuenta centavos, a él le pagaban ocho pesos [...] La gente lo respetaba y yo me sentía orgulloso, por ejemplo cuando mi madre me mandaba a comprar algo, los vendedores no me recibían el dinero, decían que ellos se arreglaban con Fidel [...] Los demás [la gente del aserradero] portaban pantalón de peto o calzón de manta y sombrero [los campesinos] y él vestía de casimir [...] Para entonces mi mamá y él despilfarraban mucho el dinero, ya que se iba muy seguido, con toda la familia a visitar a una de sus hermanas que vivía en México, y él se iba a visitar a sus padres que vivían en Tingambato, además de comprar ropa y zapatos caros. ${ }^{44}$

Las diversiones que había en aquel lugar eran varias: algunas familias solían ir al cine o de compras a Ario de Rosales cuando recibían su salario. ${ }^{45}$ Otros simplemente salían a la plaza del lugar a sentarse y platicar con los vecinos. Los niños y algunos adultos casados jugaban canicas, rayuela, trompos o construían sus propios ar-

${ }^{44}$ Las mujeres usaban enredos, falda blanca con pasteloncitos, ceñídor o faja y rebozo de bolitas. José Martínez Arias, op. cit.

${ }^{45}$ Para ese entonces Ario de Rosales era una ciudad con mucha actividad económica. 
Figura 9. Salud Arias (derecha de la fotografía), hijos y otros familiares, 1938 (Archivo la familia Arias).

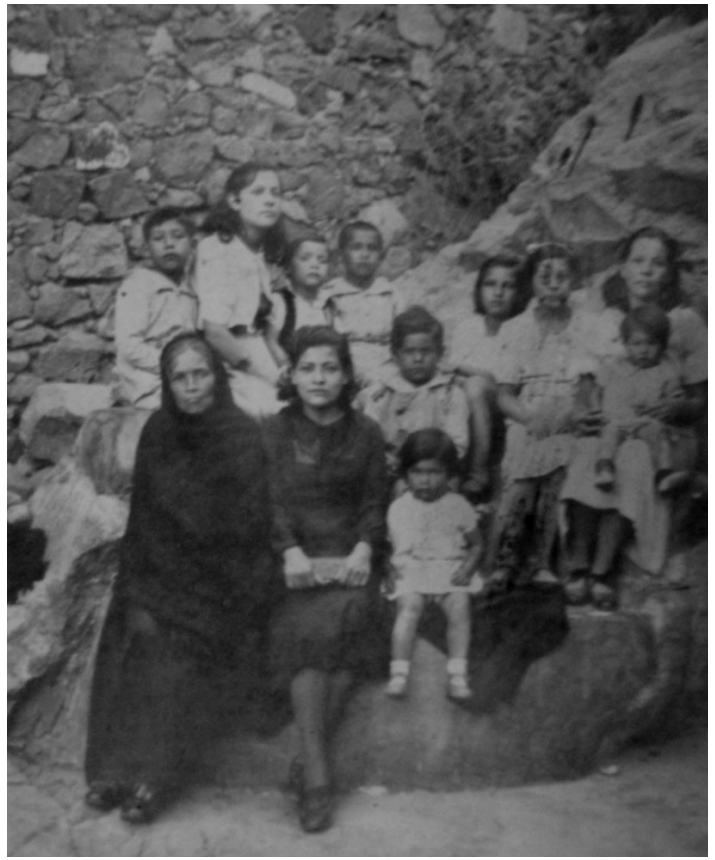

tilugios. El señor Ignacio Campos comenta que una de sus diversiones y la de otros nińos era "mosquearse" (treparse) al tren cuando empezaba a avanzar: "Comenzaba muy lento y ya cuando iba a darle más recio nos bajábamos”. ${ }^{46}$

Algunos trabajadores del aserradero pertenecían a un equipo de béisbol, incluso tenían uniforme, mientras que otros, como los hijos de Santiago Slade y sus amigos solían ponerse sus botas y gorras, montar a sus caballos e irse de cacería de venados o conejos. "una vez uno de ellos mató por accidente a un burro y tuvieron que pagárselo al dueño, antes de meterse en problemas". ${ }^{47}$

${ }^{46}$ Ignacio Campos Campos, op. cit.

${ }^{47}$ José Martínez Arias, op. cit. 
Figura 10. Salud Arias y su comadre Aurora, 1940 (Archivo de la familia Arias).

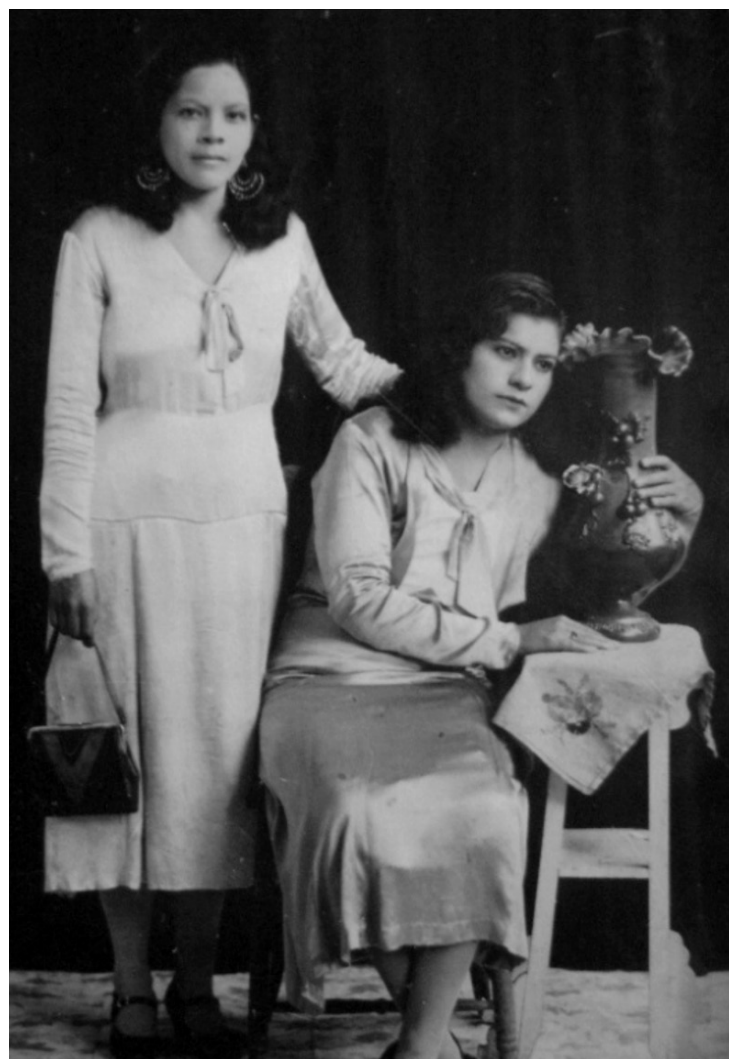

Uno de los pasatiempos donde participaban todas las familias trabajadoras del pueblo era construir papalotes y hacerlos volar durante los meses que más sopla el viento. Pero sin duda, una de las diversiones preferidas de la gente era el recreo en el "pinal": los domingos, la gente construía unos sencillos carros de madera (que ahora les llaman avalanchas) y subían a una colina que llamaban pinal, para deslizarse cuesta abajo. Señores, señoras, jóvenes y niños por igual trepaban a los carros, mientras el resto de la gente estaba sentada comiendo cañas de castilla y divirtiéndose con el 
espectáculo. ${ }^{48}$ Otras de las diversiones eran las fiestas que se celebraban en el pueblo. A pesar de que los dueños eran norteamericanos, no se oponían cuando la gente festejaba el 16 de septiembre, el 20 de noviembre y 5 de mayo, entre otros. Esta última era de las más importantes: los trenes y máquinas pitaban durante horas, todas las calles se adornaban con gusanos de huinumo, se realizaba un desfile conmemorativo, había banda de música, comida y bebi$\mathrm{da}$, hasta tarde.

Pero en aquel tiempo de postrevolución, no todo era diversión. Entre agraristas y sinarquistas, los conflictos políticos eran comunes en Michoacán. A don José le toco vivir un episodio de violencia desagradable:

Un día la gente empezó a decir que un tal Almazán, que en ese entonces se andaba lanzando para presidente de la república, ofrecería un mitin en la plaza del pueblo. Mucha gente acudió a la cita con la esperanza de escuchar las propuestas de aquel hombre y su equipo de trabajo. Mi abuela, como mucha gente llegó al lugar y yo la acompańaba. Estaban los políticos en el estrado, cuando se escuchó un disparo y uno de ellos cayó muerto. Inmediatamente toda la gente comenzó a correr despavorida, mientras se escuchaban más balazos. Yo tuve tanto miedo que comencé a correr y hasta olvidé que iba con mi abuela. A los que les preguntaban que había pasado exclamaban: ¡hubo una balacera, son los sinarquistas! $!^{49}$ Unos vecinos, que ignoraban lo sucedido, traían coche y al ver la confusión me invitaron a subir, pero preferí seguir corriendo que subirme a ese carro tan lento. Para cortar camino a mi casa cruce por una propiedad privada donde había perros, pero con mi apuración poco me importaron. Cuando llegué a mi casa me encontré con la noticia que mi madre también había ido a la reunión y me dio miedo que le hubiera pasado algo. A los pocos minutos llegó mi abuela y mi madre lo que me tranquilizó [...] Poco después se supo que habían muerto varias personas. ${ }^{50}$

48 "A las orillas del pueblo había muchos cerezos que cualquiera podía llegar y cortarlos. Yo siempre quise tener uno en mi casa, pero los plantamos poco antes de venirnos y ya no lo disfruté". José Martínez Arias, op. cit.

${ }^{49}$ Unión Nacional Sinarquista, creada en 1937.

${ }^{50}$ José Martínez se refiere a Juan Andreu Almazán, quien se lanzó como candidato 
Otro de los conflictos de aquellos tiempos eran los ocasionados por los llamados Cristeros, quienes entre 1926 y 1940 asesinaron personas, destruyeron ejidos, se apoderaron de cosechas, incendiaron bosques y hasta destruyeron parte de las vías férreas de Ajuno a Uruapan, de Ajuno a Pénjamo y obstruyeron las obras del ramal de Ajuno a Ario de Rosales, cortando las líneas telegráficas y telefónicas. ${ }^{51}$

\section{LO QUE PASÓ CON EL CIERRE DEL ASERRADERO}

Cuando cerró el aserradero de Slade, prácticamente se desintegró el pueblo nuevo de Zatzio, y cada familia "se las arregló" como pudo. Algunos se regresaron a sus respectivos pueblos, otros se fueron a buscar fortuna a diferentes ciudades, pueblos o a los Estados Unidos. La familia de Jesús Guerrero y su esposa Guadalupe Guillén, ${ }^{52}$ así como la de Fernando Guerrero, y otras, se mudaron a Pátzcuaro a buscar nuevas oportunidades. Más tarde Fernando Guerrero también tuvo que ir a buscar trabajo al país vecino del norte, mientras que Miguel Guerrero, sobrino de don Fernando, fue a buscar oportunidades a Guadalajara; después anduvo en algunas comunidades costeras, antes de establecerse definitivamente en Pátzcuaro. Un hermano menor de Miguel se fue a los Estados Unidos y allá falleció. ${ }^{53}$

Los miembros de la familia Arias, por su parte, anduvieron errantes varios ańos. Buscando oportunidades de trabajo pasaron por Maluco, Villa Madero, Janámaro y Adelaida, Tamaulipas, donde se decía que el señor Slade tenía otro aserradero. ${ }^{54}$ Muchos creían que ese aserradero estaría mejor que el de Zatzio pero no fue así y hubo poca fortuna. Para 1943, se mudaron a Pátzcuaro y al año siguiente Salud y Fidel se separaron. Habían recorrido al menos cua-

presidencial en 1940. Cabe mencionar que se supo de otras "matanzas" en Tacámbaro y en la ciudad de México, causadas por enemigos de Almazán.

${ }^{51}$ Pablo G. Macías, op. cit., p. 347.

52 Guadalupe Guillén actualmente (agosto de 2009) vive en Pátzcuaro y tiene 95 años de edad.

${ }^{53}$ Miguel Guerrero, op. cit.

54 "En Adelaida estuvimos un año. Don Miguel, que había trabajado en Zatzio, fue el encargado de instalar el nuevo aserradero. Ahí no había trenes, pero sí muchas trocas para cargar el trozo". José Martínez Arias, op. cit. 
tro lugares en sólo tres años. José Martínez comenta: "Al cerrarse nos fuimos al Maluco, ya que Padilla, un ex vecino y amigo de la familia abrió un aserradero con un dinero que se encontró". ${ }^{55}$ Cuando la familia Arias llegó a Pátzcuaro venían padeciendo fuertes problemas económicos. En tiempo de abundancia pensaron poco en el ahorro y, ahora, lo estaban padeciendo. ${ }^{56}$ Por falta de dinero para comprar medicina, no pudieron evitar la muerte de dos niños, hijos de la señora Salud Arias, hermanos de Cecilia, Amelia, Javier y Alicia, y medios hermanos de José y Julia. ${ }^{57}$ En Pátzcuaro no había trabajo, parecía un pueblo fantasma: "logré entrar a trabajar en un aserradero, pero no era un empleo fijo a veces trabajábamos y otras veces nos descansaban por días o semanas". ${ }^{58}$ Esta situación desesperante motivó a José, de 14 años, que ahora era el "hombre" de la casa a irse de "mojado" a los Estados Unidos. "Primero me fui sin dinero y logre llegar a Texas, donde estuve varios años, luego me pasé a California [...]". Pero las cosas no mejoraron inmediatamente y tuvieron que pasar varios ańos de miseria, hambre y sufrimiento, antes de que el panorama mejorara.

\section{Comentarios finales}

La explotación de los bosques de Michoacán, en la primera mitad del siglo xx, fue contundente y reflejó la dinámica social, política y económica de la época, donde los grupos de poder obtuvieron los mejores beneficios, mientras que las comunidades y los recursos naturales venían a menos. Aunque en 1882 se había declarado un decreto para legislar la explotación irracional de los bosques en $\mathrm{Mi}$ choacán, que obligaba a los ayuntamientos a informar sobre la manera en cómo se aprovechaban los montes, sobre nuevos plantíos y

${ }^{55} \mathrm{Idem}$.

56 "Algunos de los que ganaban \$2.50 compraron casa. Donato Gaspar, por ejemplo, compró casa y carro, mientras que Fidel se quedó sin nada”. Idem.

57 “Murieron de Disentería. El niño tenía 3 ańos y la nińa 2". Idem. Arellano, Alicia, media hermana de José Martínez Arias y de los niños. Entrevista hecha por J. Manuel M. Aguilar, julio de 2009.

${ }^{58}$ José Martínez Arias, op. cit. 
sobre abusos de algún tipo, entre otras cosas; no hubo manera de contener la excesiva extracción de especies madereras por parte de empresarios nacionales y extranjeros, sobre todo al haberse originado el arrendamiento como una nueva fisionomía en el sistema capitalista de producción a finales del siglo XIX.

$\mathrm{Al}$ igual que la formación y desaparición de este asentamiento en las cercanías de Ario de Rosales, en las primeras décadas del siglo XX se formaron pequeñas villas del mismo tipo en varias partes del estado. Así, la explotación de los recursos madereros se volvió excesiva, pues "se cortaban los árboles maduros en grandes cantidades por lo que comenzó a escasear la buena madera, pero no se plantaban los nuevos árboles que la compañía estaba obligada o se plantaban muy pocos, sin cuidar que éstos prendieran", 59 por lo que algunas comunidades vieron la imposibilidad de extraer especies como el pino y el oyamel, que en otro tiempo abundaban. ${ }^{60}$

Si bien es cierto que las políticas de Aristeo Mercado perjudicaron a varios pueblos indígenas, al obligarlos a perder sus serranías para cederlas a bajo precio a Santiago Slade y enriquecer de paso a sus favoritos que intervinieron en el negocio, ${ }^{61}$ los favoritismos y la corrupción continuaron mucho después de Porfirio Díaz y el gobernador Mercado, aun después de las leyes promovidas por Lázaro Cárdenas (como la 46 de 1931), ${ }^{62}$ El panorama mostrado parece ser el reflejo de lo que aún no se ha superado: leyes que se promulgan, pero que no se respetan, la tala clandestina cobijada por los grupos de poder, en medio de corrupción e impunidad, donde muchas veces las comunidades rurales, aun con los problemas y disputas internas, son las menos favorecidas. Es decir, con el cierre de los

${ }^{59}$ Ignacio Ríos (falleció en 2004), de 81 años, originario de Paracho, Mich. Entrevista hecha por J. Manuel Martínez en julio de 2002.

${ }^{60}$ Tal fue el caso de la sierra purépecha. Patricia Ávila, La problemática regional del agua y sus implicaciones ambientales: el caso de la Meseta Purépecha, México, El Colegio de México, 1988, 85.

${ }^{61}$ Álvaro Ochoa Serrano, Repertorio michoacano 1889-1926, Zamora, El Colegio de Michoacán, 1995, 15.

${ }^{62}$ En 1929 Lázaro Cárdenas inició un proyecto para anular contratos de arrendamiento de bosques y organizar cooperativas para una explotación más eficaz de los bosques, lo cual derivó en la ley 46 de 1931. Eitan Gitzberg, op. cit., p. 210. 
aserraderos de Santiago Slade no se terminaron los problemas del bosque de la región, ya que durante todo el siglo xx y lo que va del xxI se observa un rápido proceso de deterioro ambiental causados por el cambio de uso del suelo, plagas, enfermedades, incendios, apertura de caminos, tendido de líneas de transmisión y por supuesto, clandestinaje de madera. ${ }^{63}$

Desgraciadamente, no existen cifras exactas que nos indiquen la cantidad de árboles talados por las compañías de Slade o hectáreas de bosque explotadas en comparación a las reforestadas, sin embargo, se sabe que la extracción de maderas fue un negocio, no sólo para compañías como la de Slade, que generaban ganancias por miles de pesos al año ${ }^{64}$, sino para el gobierno que recibía grandes cantidades como pago de impuestos. ${ }^{65}$

Por último, es importante mencionar que, al margen de lo que significaba la extracción de madera en la economía, la política, y el medio ambiente de la región, la gente que trabajó en el aserradero de Zatzio y que habitó el pueblo construido por orden del empresario, tuvo una visión mayormente positiva de los beneficios inmediatos que obtuvieron al participar con dicha compañía o estar inmersa en la dinámica social que se originó con su establecimiento.

\section{Bibliografía CITADA}

Ávila, Patricia, La problemática regional del agua y sus implicaciones ambientales: el caso de la Meseta Purépecha, México, El Colegio de México, 1988.

Boehm de Lameiras, Brigitte et al., coord., Michoacán desde afuera, México, El Colegio de Michoacán, Gobierno del Estado de Michoacán, 1995.

${ }^{63}$ Omar Masera et al., Dinámica y uso de los recursos forestales de la región purépecha, Morelia, Gira, 1998, 19.

${ }^{64}$ La producción forestal en Michoacán de 1932 a 1934, por ejemplo, ascendía a $\$ 20,312,440$, Fernando Foglio Miramontes, Geografía económico agrícola del Estado de Michoacán, tomo II, México, Secretaría de Agricultura y Fomento de Economía Rural, 1936, 72.

${ }^{65}$ Por ejemplo, se sabe que las recaudaciones que tuvo el Gobierno del Estado de Michoacán, entre los años 1924 a 1928, relacionadas con la explotación del bosque fueron de \$786,745.69. María Leticia, op. cit., p. 173. 
Castillo Janacua, J. Jesús, Paracho durante la revolución, Estampas y relatos 1890-1930, Morelia, Baisal editores, 1988.

DiETz, Gunther, La comunidad P'urhépecha es nuestra fuerza: etnicidad, cultura y región en un movimiento indígena en Michoacán, México, Quito, Abya-Yala, 1999.

Escobar Ohmstede, Antonio, Estudios campesinos en el Archivo General Agrario: Finqueros extranjeros en Soconusco, legislación y colonización, 1875-1910, México, Ciesas, 1998.

Espín DíAz, Jaime L., Tierra fría, tierra de conflictos, Zamora, El Colegio de Michoacán, 1986.

Florescano, Enrique, coord., Historia general de Michoacán, vol. IV, Morelia, Gobierno del Estado de Michoacán, Instituto Michoacano de Cultura, 1989.

Foglio Miramontes, Fernando, Geografía económico agrícola del Estado de Michoacán, México, Secretaría de Agricultura y Fomento de Economía Rural, 1936.

FujIGAKY CRUz, Esperanza, Historia de la cuestión agraria mexicana (1890-1910), México, Siglo XXI, CEHAM, 1998.

Galván Silva, María Leticia, Inversiones extranjeras en Michoacán 1911-1940, Tesis para obtener el título de licenciado en Historia, Morelia, Escuela de Historia, UMSNH, 2002.

García López, Lucía, Nahuatzen, agricultura y comercio en una comunidad serrana, Zamora, El Colegio de Michoacán, Conacyt, 1984.

Garciadiego, Javier, coord., Gran historia de México Ilustrado, vol. IV, México, Planeta Agostini, Conaculta-INAH, 2006.

GitzBerg, Eitan, Lázaro Cárdenas Gobernador de Michoacán 19281932, Morelia, El Colegio de Michoacán, umsnh, 1990.

Guzmán Ávila, J. Napoleón, Michoacán y la inversión extranjera 1880-1911, Morelia, UMSNH, Departamento de Investigaciones Históricas, 1982.

Hurtado Torres, Leticia, Memoria fotográfica de Ario de Rosales, Morelia, SECUM, 2010.

Macías, Pablo G., Ario de Rosales, Monografias Municipales del Estado de Michoacán, Morelia, Gobierno del Estado de Michoacán, 1980. 
Masera, Omar et al., Dinámica y uso de los recursos forestales de la región purépecha, Morelia, Gira, 1998.

Ochoa Serrano, Álvaro, Repertorio Michoacano 1889-1926, Zamora, El Colegio de Michoacán, 1995.

Paredes Martínez, Carlos y Martha Terán, coords., Autoridady gobierno indigena en Michoacán, Zamora, El Colegio de Michoacán, INAH, UMSNH, 2003.

Romero Flores, Jesús, Diccionario michoacano, historia y geografía, Morelia, Gobierno del Estado de Michoacán, 1960.

Sánchez Díaz, Gerardo, coord., Pueblos, villas y ciudades de Michoacán en el porfiriato, Morelia, UMSNH, CIC, IIH, 1991.

Vargas Uribe, Guillermo et al., Apuntes e indicadores para la historia ambiental del estado de Michoacán, Morelia, Centro de Investigaciones Económicas y Sociales, Escuela de Economía, Facultad de Biología, UMSNH, Instituto Michoacano de Cultura, 2000.

VÁzQuez, Luis, Antropología politica de una comunidad indigena en Michoacán, Morelia, sEP, 1985.

\section{Fuentes DOCUMENTALES}

Archivo General e Histórico el Poder Ejecutivo de Michoacán: AGHPEM.

Archivo General de Notarias del Estado de Michoacán: AGNM.

Archivo Histórico del Poder Judicial: AHPJ.

FECHA DE RECEPCIÓN DEL ARTÍ́CULO: 1 de octubre 2009

FECHA DE ACEPTACIÓN Y RECEPCIÓN DE LA VERSIÓN FINAL: 13 de febrero de 2011 